\title{
Production of Biopolymer from Bacteria - A Review
}

\author{
Ranganadha Reddy Aluru ${ }^{1 *}$, Sravani Koyi ${ }^{1}$, Sanjana Nalluru ${ }^{1}$, Chandrasekhar Chanda ${ }^{2}$ \\ ${ }^{1}$ Department of Biotechnology, VFSTR, Vadlamudi, Guntur 522213, Andhra Pradesh, India \\ ${ }^{2}$ Department of Biotechnology, Koneru Lakshmaiah Education Foundation, Guntur 522502, Andhra Pradesh, India
}

Corresponding Author Email: arr_bt@vignan.ac.in

https://doi.org/10.18280/eesrj.080205

Received: 10 March 2021

Accepted: 29 May 2021

\section{Keywords:}

polyhydroxyalkanoates, bacteria, biopolymer, bioplastic, polyhydroxubutyrate

\begin{abstract}
Polyhydroxyalkanoates (PHA) producers have been found in a variety of ecological niche's that are naturally or unintentionally exposed to high organic matter or growth limiting substances such as dairy wastes, hydrocarbon contaminated sites, pulp and paper mill wastes, agricultural wastes, activated sludges of treatment plants, rhizosphere, and industrial effluents. Few of them also create extracellular byproducts such as rhamnolipids, extracellular polymeric compounds, and biohydrogen gas. These microbes can use waste materials of various origin as substrates while producing valuable bioproducts such as PHB. As a result, these microbes are industrially important candidates for production; Implementation of an integrated system to separate their byproducts (intracellular and extracellular) could be an economical method. In this study, we reviewed several microorganisms that live in diverse environmental situations and are stimulated to collect carbon as polyhydroxyalkanoates granules, as well as variables that influence their production and composition. Ultimately, the current cost of bioplastic manufacture from stored PHA granules can be decreased by investigating capabilities such as dual generation of microorganisms and utilization of wastes as renewable substrate under optimal growth conditions in either a batch or continuous process.
\end{abstract}

\section{INTRODUCTION}

Feasibility, concerns related to environment as well as the design of chemical products and processes that reduce the use or generation of hazardous substances in the coming years have played a vital role in developing a newer generation of processes, products as well as materials. There has been a steady decline in the petroleum assets and landfill space due to the tenacity of different plastics in the environment. A need arises to develop polymers that are biodegradable from the renewable resources due to the damage the toxic gases cause during the ignition process. To replace petroleum feedstock a renewable resource i.e., agricultural and biomass feedstock have been found to have potential to be used in eco-efficient packaging [1]. Biopolymers that are acquired from marine prokaryotes both Bacteria and Archaea have showed promising material possessions and commercial aspects. From various studies it has been understood that during severe stress conditions many marine microbes pile upon poly- $\beta$ hydroxybutyrate particles that are intracellular because these particles are the reserves for carbon and energy inside the cells. One of the potent materials for biodegradable plastics is polyhydroxyalkanoates even though they play an entirely different role in prokaryotes they are an effective base material for the production of biodegradable plastics.

The PHB can be synthesized under stressful conditions like limited nitrogen source and excess of carbon hence can be used for industrial exploitation. But under incredibly stressful conditions like sodium chloride stress, stress of heat and chilling as well as under insufficient conditions of calcium, magnesium and potassium negative effects are seen for the collection of PHB.
The accumulation of PHB up to $29 \%$ dry cell weight was seen by studies with Synechocytis sp. PCC 6803, when in phosphate and gas exchange limitation as well as with a presence of $0.4 \%$ acetate and glucose [2]. The accumulation of PHB has been boosted to $43 \%$ dry cell weight in Nostoc muscorum by the supplementation of $0.4 \%$ acetate, under chemoheterotrophy. 65\% dry weight of PHAs in bacterial strain Haloferax mediterraneiin phosphate limiting conditions and glucose or sucrose as best carbon source was achieved by Garcia Lillo and Rodriguez-Valera [3-5]. Many products that range from adhesives to emulsifiers are made by exploiting the features like exopolysaccharides, Polyhydroxtbutyratye and melanins that are the reason for the survival of marine organisms [6-12].

\section{CHEMICAL COMPOSITION AND PHYSICAL PROPERTIES}

PHAs are one of the best contenders in biodegradable plastics due to their ample biodegradability and similarity to the commercially produced plastics [13]. PHA is Polyhydroxtbutyratye (PHB) it's one of the most commonly used polymers and its metabolic pathway can be explained in a brief [14]. A relation between PHB properties to various synthetic plastics including polypropylene was shown. Polyesters like polyhydroxyalkanoates (PHAs) are accumulated by bacteria under unhinged growth conditions of carbon substrate as well as other nutrients like sulphur, nitrogen, phosphorus or oxygen [15]. Elastomeric polyesters (polyoxo esters) of R-hydroxyalkanoic acid (HA) monomers are PHAs. Based on the structure polymers can be classified. The number 
of carbon atoms range from 4-14. Another way to classify polymers is based on the type of monomer, either producing homopolymers or heteropolymers. PHAs with 3-5 carbons are short chain length PHAs (scl- PHAs). Examples of this class include Poly (3- hydroxybutyrate), $\mathrm{P}$ (3HB) and poly (4hydroxybutyrate), P (4HB) [16]. Medium chain length PHAs (mcl- PHAs) are the PHAs with 4-14 carbon atoms. Examples are Poly (3- hydroxyhexanoate), $\mathrm{P}(3 \mathrm{Hx})$, poly (3hydroxyoctanoate), $\mathrm{P}(3 \mathrm{HO})$ and heteropolymers like $\mathrm{P}(3 \mathrm{HHx}-$ co-3HO). The PHAs that have more than 15 carbon atoms are called long chain length (lcl- PHAs). The medium chain length PHAs and short chain length PHAs differ in the physical properties including poly (3- hydroxybutyrate) (PHB) which is crystalline and stiff material due to their structural differences. However, medium chain length PHAs show elastomeric properties. The long chain saturated and unsaturated monomers have different properties where the double bonds clinch the opportunity for more chemical alterations due to inherent biocompatible and biodegradable nature of the PHAs they contain. One of the best studies polymers belonging to the PHA biopolymer family is the polymer polyhydroxybutyrate. PHB has a linear structure that displays $60-70 \%$ crystallinity, as a homopolymer. Due to robust intermolecular interaction, the high melting temperature results in the variation between the two temperatures. When compared with commercial polymers, polymerization with comonomers can eradicate these problems with pure PHBs [17]. Under antagonistic environmental conditions, the survival of microbes can be augmented by the accumulation of PHA [18]. Due to the high assorting and perplexing environments microbial strains can be used as a source for isolating the novel PHA [19]. Only a little information was found on the on the microorganisms that produce PHA until recently [20]. Among the commensally heterotrophic bacteria, vibrios were said to be assertive. Improvement of several PHA accumulating strains can be aided by the marine ethnic environment. The PHA accumulating strains may contain species other than vibrio [21]. Intensive studies have been conducted by both researchers and industrialists on petrochemical polysters due to their similarity of PHAs. PHAs are therefore, considered to be good candidates for elastomers as well as biodegradable plastics [22].

\section{BIOSYNTHETIC PATHWAY OF BIOPOLYMER PRODUCTION}

Lemoigne discovered homopolymer PHB in the year 1920s in the bacteria Bacillus megaterium. In prokaryotic cells the Polyhydroxyalkanoates (PHA) act as carbon and energy reserves [16]. When excess of carbon is provided during the inqdequate growth nutrient availability a variety of bacteria accumulate them [23, 24]. PHA synthase $(\mathrm{PhaC})$ is a requirement for synthesizing PHA.B-hydroxyacyl-coenzyme A substrates is used by the enzyme PhaCfor the polymerization process. Such substrates are produced in various pathways using the enzymes b-ketothiolase (encoded by phaA) and acetoacetyl-CoA reductase (encoded by phaB), b-oxidation, and de novo synthesis of fatty acid pathway [25, 26]. Using a diverse number of bacteria more than 20 different varieties of PHA synthesis operons have been cloned and analysed. A divergence has been noticed when the proteins were analyzed which play a vital role in the biosynthetic pathways. The synthesis of PHA takes place in three steps with the reaction initiated by two acetyl-CoA from tricarboxylic acid cycle (TCA). b-thiolase (PhaA) enzyme, then condensed to acetyl-CoA acetoacetyl-CoA. NADHdependentenzymeacetoacetyl-CoAreductase (phaB) reduces it at position 3 as shown in Figure 1. Polymerase (PhaC) esterifies the monomers to the PHB polymer in the step. The only place this step takes place is in the granular surface. The intracellular mediation of acetyl-CoA controls the formation of PhaB. Without restricting any nutrients the pool of CoASH is enhanced in growth conditions during the exponential growth phase. However, PHB synthesis is favored when the growth is restricted for nutrients e.g. CoASH level condensed by phosphate or ammonium. Under oxygen limitation, a high PHB content was found and implicated as a substitute electron sink for tumbling equivalents [27].

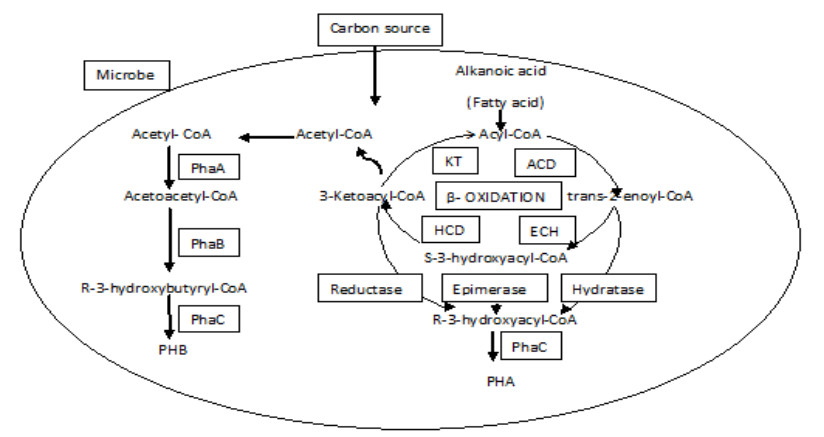

Figure 1. Biosynthetic pathway of Biopolymer in microbes

\section{DETECTION AND ANALYSIS OF BIOPOLYMER}

The occupancy of PHA is not only limited to intracellular assortment in bacteria and granules. Marine bacteria such as Bacillus subtilis and Streptomyces lividans which are closely related to calcium and polyphosphate ions have been found to have PHB with less molecular weight [28]. Studies show that cPHB is not only present in eubacteria but also present in eukaryotic cells like yeast, sheep (intestine) cat muscles and many more. Hence, it can be understood that PHB is biocompatible with the animals [29]. By using easy staining methods the PHB were detected in the marine microbes. Sudan Black staining methods other than Nile blue can be used for phenotypic detection of intracellular PHA. These staining methods are sensitive but it takes time and is very strenuous to screen a lot of environmental isolates [30, 31]. By using Nile blue A or Nile red staining the colonies or bacteria growing in plates can be fluorescently viewed by using UV illumination. Large number of bacterial strains can be stained by using the above mentioned colony staining method. Still it is mandatory that for accumulation of PHA granules suitable carbon sources are required which is followed by lengthy incubation period $[32,33]$. The double bonds present in monomers of monounsaturated 3-hydroxyalkenoic acids can be localized and detected by using a new gas chromatography-mass spectrometry (GC-MS) technique [34].

\section{BIOPOLYMER AND MICROBES}

Significant and incipient biological resources are exploited to marine biopolymers. Made from petroleum, Polyhydroxtbutyratye is a biomedical material that is eco 
friendly and also has the potential to replace plastics. It can be used in surgical pins, stapes, blood vessel replacements, bone replacements and plates, medical implant and drug delivery devices due to its biodegradable and biocompatible nature.
Numerous marine micro organisms including marine actinomycetes, algae and halophilic bacteria synthesize polyesters called polyhydroxyalkanoates (PHAs), as mentioned in Table 1.

Table 1. PHB production by various bacteria

\begin{tabular}{|c|c|c|c|c|}
\hline Microorganism & Carbon source & PHA & $\begin{array}{c}\text { PHA content } \\
(\% \mathrm{w} / \mathrm{v})\end{array}$ & references \\
\hline Acinetobacter nosocomialis $R R 20$ & Molasses & PHB & $7.8 \%$ & [35] \\
\hline Cupriavidus necator & Glycerol & PHA & $62 \%$ & [36] \\
\hline Bacillus firmus NII 0830 & Rice straw & PHB & $89 \%$ & [37] \\
\hline Cupriavidus necator & Date seed & PHB & $73 \%$ & [38] \\
\hline Bacillus subtilis NG220 & Molasses & PHB & $51.8 \%$ & [39] \\
\hline Acinetobacter junii BP25 & Rice mill effluent & PHB & $94.28 \%$ & [40] \\
\hline Rhodococcus equi & Palm kernel oil & PHB & $38 \%$ & [41] \\
\hline Ralstonia eutropha ATCC 17699 & Rice paddy straw & PHB & $75.45 \%$ & [42] \\
\hline Vibrio harveyi MCCВ 284 & Glycerol & PHB & $72 \%$ & [43] \\
\hline Alcaligenes $s p$ & Molasses & PHB & $76.8 \%$ & [44] \\
\hline
\end{tabular}

\section{MECHANISM OF BIOPOLYMER PRODUCTION}

For coping with the depleted nutrient conditions different marine archae and bacteria which includes various Halomonas species accrue poly-b-hydroxyalkanoates (carbon and energy storage materials). To avoid molecular impairment caused due to cellular freezing and dehydration definitive osmotic adaptations are developed in many of the marine strains. The approaches comprise of (i) Osmotic pressure balance over certain transmembrane exchange of salts and transport proteins and (ii) Aggregation of protective compatible solutes like betaine or ectaine. The appropriate solutes of Halomonas species are accumulated by uptake or by synthesis. Before in Haloarculamarismortui, a holoarchaeathe PHA granules were seen whereas many halophiles were used for the accumulation of PHB [45]. Recently the use of few halophiles for the production of PHA and characterization of copolymers was studied [46]. The use of marine micro organisms for producing PHB has been gaining lot of attention due to their lowering fermentation and cost effectiveness [47]. Due to less contamination possibility by other microbes due to the increased salt concentrations the cost for the sterilization process also has decreased. In salt deficient water by using the osmotic shock treatment causes lysis of the haloarchae cells due to which there is reduction in costs for the recovery of polymers. After the fermentation process the concentrated residual salt present in the broth can be recycled thereby reducing the cost of p-production. This avoids the ecological snags that cause the waste product depletion. In Halomonas elongate the gene clusters like pha (responsible for PHA synthesis), ect. (responsible for ectoine synthesis), phaC (coding for PHA synthase) and phaP (coding for phasing) were well preserved according to the comparative genomic investigations. From the preservation it was understood that the adaptable success and colonization competency of the Halomonas species maybe due to the selective stress wielded on these genes [45].

\section{BIOCOMPATABILITY OF BIOPOLYMER}

The biocompatible nature of PHA in invitro conditions has been demonstrated at various cell cultures like fibroblasts, mesenchymal stem cells, osteoblasts, bone marrow cells, articular cartilage chondrocytes, endothelial cells, smooth muscle cells, etc. The cell cultures isolated from kidneys of monkeys, AGMK and FRLK4 which were grown on PHB films in the form of scaffolds for 360 days also proved to be biocompatible of PHB. During the whole time of incubation of cell culture it was found that the growth and cell viability was not improved by PHB. The cells did not display any polymeric dependent factors such as toxic substance deliverance (polymer destruction production), incompatible surface of polymer etc. The growth, enlargement and migration of cells are not influenced by the cytotoxic nature of PHB films at the cell culture. Hence, PHB was found to be biocompatible and biologically inert for the isolated cell cultures in invitro conditions [48]. PHA is considered to be a substitute for synthetic plastics derived from petroleum and also has been found to have a wide array of use in aquaculture, agriculture, medicine, tissue engineering, antifouling, pharmacy, food industry, raw material for enantiomerically pure chemicals, and the paint industry as well [49]. One of its major limiting factors is the cost production of PHB, which constrains its commercial applications. Hence, it has been inevitable to use an economical process for the hyper producing strains for the development of PHB as ecofriendly plastics for commercial use [50-56].

\section{CONCLUSION}

An alternative to petroleum-derived plastics is a biodegradable stored substance of microbes known as PHA. There is a dire need for an integrated system that facilitates the separation of high-valued microbial synthesised products at a decreased cost production. Due to the excess presence of carbon, under environmental stress some microbes reportedly produced PHA intracellularly along with the simultaneous production of other metabolites. The effect of PHA production on growth kinetics resulted in a stationary phase for most of the reported cases. These significantly remarkable byproduct's that are produced biologically require well established industrial processes, which in turn lead to an increase in the production cost. The onset of research on simultaneous production of polymeric substances (intracellularly as well as extracellularly) makes a path to a new way of understanding the metabolic links and ecological 
prospects (i.e., defining role, diversity and evolution). During the simultaneous production of high valued Endo polymers and exopolymers, by using the same organism under optimised conditions, we can also use waste (domestic, agricultural, or industrial effluents) which will help us resolve issues of environmental pollution, decreased cost production and will help with commercialisation in the market. Thus, we can ponder upon the question: "is waste really useless?" In relation to the production of high-value products from the residing microbes present in the waste.

\section{ACKNOWLEDGMENT}

The author acknowledges VFSTR (Deemed to be university) and DST-FIST networking facility to carry out this work.

\section{REFERENCES}

[1] Vasile, C. (2009). Environmentally degradable polymeric materials: definition and back-ground. Environmentally Degradable Materials Based on Multicomponent Polymeric Systems, Koninklijke Brill NV, Leiden, Netherlands.

[2] Panda, B., Mallick, N. (2007). Enhanced poly- $\beta$ hydroxybutyrate accumulation in a unicellular cyanobactrium, Synechocystis sp. PCC 6803. Letters in Applied Microbiology, 44(2): 194-198. https://doi.org/10.1111/j.1472-765X.2006.02048.X

[3] Bhabatarini, P., Praveen, J., Laxuman, S., Nirupama, M. (2006). Optimization of Cultural and Nutritional Conditions for Accumulation of Poly-BetaHydroxybutyrate in Synechocystis Sp. PCC 6803. Bioresource Technology, 97(11): 1296-1301. https://doi.org/10.1016/j.biortech.2005.05.013

[4] Sharma, L., Mallick, N. (2005). Enhancement of poly- $\beta$ hydroyxybutyrate accumulation in Nostoc muscorum under mixotrophy, chemoheterotrophy and limitation of gas exchange. Biotechnology Letters, 27(1): 59-62. https://doi.org/10.1007/s10529-004-6586-1

[5] Garcia Lillo, J., Rodriguez-Valera. F. (1990). Effects of culture conditions on poly( $\beta$-hydroxybutyrate acid) production by Haloferax mediterranei. Applied and Environmental Microbiology, 56(8): 2517-2521. https://doi.org/10.1128/aem.56.8.2517-2521.1990

[6] Labare, M.P., Guthrie, K., Weiner, R.M. (1989). Polysaccharide exopolymer adhesives from periphytic marine bacteria. Journal of Adhesion Science and Technology, 3(1): 213-223. https://doi.org/10.1163/156856189X00173

[7] Sandford, P.A. (1984). Biotechnology of Marine Polysaccharides. In: R.R. Colwell, E.R. Pariser, A.J. Sinksey (Eds.), McGraw-Hill, 454-516.

[8] Zuckerberg, A., Diver, Z., Peeri, D.L., Gutnick, E. (1979). Rosenberg, Emulsifier of Arthrobacter RAG-1: Chemical and physical properties. Applied and Environmental Microbiology, 37(3): 414-420. https://doi.org/10.1128/aem.37.3.414-420.1979

[9] Bell, A.A., Wheeler, M.H. (1986). Biosyntheis of fungal melanins. Annual Review of Phytopathology, 24: 411451.

https://doi.org/10.1146/annurev.py.24.090186.002211

[10] Weiner, R.M., Segall, A.M., Colwell, R.C. (1985).
Characterization of a marine bacterium associated with Crassostrea virginica (the Eastern Oyster). Applied and Environmental Microbiology, 49(1): 83-90.

[11] Bernadsky, G., Sar, N., Rosenberg, E. (1993). Drag reduction of fish skin mucus: relationship to mode of swimming and size. Journal of Fish Biology, 42(5): $797-$ 800 . https://doi.org/10.1111/j.10958649.1993.tb00385.x

[12] Anwar, S., Ali, B., Sajid, I. (2016). Screening of rhizospheric actinomycetes for various in-vitro and invivo plant growth promoting (PGP) traits and for agroactive compounds. Frontiers in Microbiology, 7: 1334. https://doi.org/10.3389/fmicb.2016.01334

[13] Luengo, J.M., Garcia, B., Sandoval, A., Naharro, G., Olivera, E.R. (2003). Bioplastics from micro- organisms. Current Opinion in Microbiology, 6(3): 251-260. https://doi.org/10.1016/s1369-5274(03)00040-7

[14] Khanna, S., Srivastava, A.K. (2005). Recent advances in microbial polyhydroxyalkanoates. Process Biochemistry, 40(2): https://doi.org/10.1016/j.procbio.2004.01.053

[15] Madison, L.L., Huisman, G.W. (1999). Metabolic engineering of poly(3 hydroxyalkanoates): from DNA to plastic. Microbiology and Molecular Biology Reviews. 63(1): 21-53. https://doi.org/10.1128/MMBR.63.1.2153.1999

[16] Anderson, A.J., Dawes, E.A. (1990). Occurrence, metabolism, metabolic role, and industrial uses of bacterial polyhydroxyalkanoates. Microbiology Reviews, 54(4): 450-472.

[17] Koning, G.D. (1995). Physical properties of bacterial poly ((R)-3-hydroxyalkanoates). Canadian Journal of Microbiology, 41:

https://doi.org/10.1139/m95-201

[18] Lopez, N.I., Floccari, M.E., Steinbuchel, A., García, A.F., Méndez, B.S. (1995). Effect of poly (3- hydroxybutyrate) content on the starvation-survival of bacteria in natural waters. FEMS Microbiology Ecology, 16(2): 95-101. https://doi.org/10.1111/j.1574-6941.1995.tb00273.x

[19] Lopez-Cortes, A., Lanz-Landázuri, A., GarcíaMaldonado, J.Q. (2008). Screening and isolation of PHB-producing bacteria in a polluted marine microbial mat. Microbial Ecology, 6: 112-120. https://doi.org/10.1007/s00248-007-9329-8

[20] Wei, Y.H., Chen, W.C., Wu, H.S., Janarthanan, O.M. (2011). Biodegradable and biocompatible biomaterial, polyhydroxybutyrate, produced by an indigenous Vibrio sp. BM-1 isolated from marine environment. Marine Drugs, 9(4): 615-624. https://doi.org/10.3390/md9040615

[21] Chandrasekaran, M., Lakshmanaperumalsamy, P., Chandramohan, D. (1984). Occurrence of vibrios during fish spoilage. Current Science, 53(1): 31-32.

[22] Poirier, Y., Nawrath, C., Somerville, C. (1995). Production of polyhydroxyalkanoates, a family of biodegradable plastics and elastomers, in bacterial and plant. Nature Biotechnology. 13: 142-150. https://doi.org/10.1038/nbt0295-142

[23] Ramsay, B.A., Lomaliza, K., Chavarie, C., Dube, B., Bataille, P., Ramsay, J.A. (1990). Production of poly-(bhydroxybutyric-co-bhydroxyvaleric) acids. Applied and Environmental Microbiology, 56(7): 2093-2098.

[24] Steinbuchel, A., Schlegel, H.F. (1991). Physiology and molecular genetics of poly (beta-hydroxy-alkanoic acid) 
synthesis in Alcaligene eutrophus. Molecular Microbiology. 5(3): 535-542. https://doi.org/10.1111/j.1365-2958.1991.tb00725.x

[25] Page, W.J., Manchak, J. (1995). The role of $\beta$-oxidation of short-chain alkanoates inpolyhydroxyalkanoate copolymer synthesis in Azotobacter vinelandii UWD. Canadian Journal of Microbiology, 41: 106-114.

[26] Rehm, B.H.A., Steinbuchel, A. (1999). Biochemical and genetic analysis of PHA synthases and other proteins required for PHA synthesis. International Journal of Biological Macromolecules, 25(1-3): 3-19. https://doi.org/10.1016/s0141-8130(99)00010-0

[27] Senior, P.J., Beech, G.A., Ritchie, G.A.F., Dawes, E.A. (1972). The role of oxygen limitation in the formation of poly-b-hydroxybutyrate during batch and continuous culture of Azotobacter beijerinckii. Biochemical Journal, 128(5): 1193-1201. https://doi.org/10.1042/bj1281193

[28] Reusch, R.N. (1999). Streptomyces lividans potassium channel contains poly-(R)-3-hydroxybutyrate and inorganic polyphosphate. Biochemistry, 38: 1566615672. https://doi.org/10.1021/bi991782f

[29] Seebach, D., Fritz, M.G. (1999). Detection, synthesis, structure, and function of oligo (3-hydroxyalkanoates): Contributions by synthetic organic chemists. International Journal of Biological Macromolecules, 25(1-3): 217-236. https://doi.org/10.1016/s01418130(99)00037-9

[30] Schlegel, H.G., Lafferty, R., Krauss, I. (1970). The isolation of mutants not accumulating poly-betahydroxybutyric acid. Archives Microbiology, 71(3): 283-294. https://doi.org/10.1007/BF00410161

[31] Ostle, A.G., Holt, J.G. (1982). Nile blue A as a fluorescent stain for poly-beta-hydroxybutyric acid. Applied and Environmental Microbiology, 44(1): 238241.

[32] Kranz, R.G., Gabbert, K.K., Madigan, M.T. (1997). Positive selection systems for discovery of novel polyester biosynthesis genes based on fatty acid detoxification. Applied and Environmental Microbiology, 63(8): 3010-3013.

[33] Spiekermann, P., Rehm, B.H., Kalscheuer, R., Baumeister, D., Steinbuchel, A. (1999). A sensitive, viable-colony staining method using Nile red for direct screening of bacteria that accumulate polyhydroxyalkanoic acids and other lipid storage compounds. Archives Microbiology, 171(2): 73-80. https://doi.org/10.1007/s002030050681

[34] Simon-Colin, C., Gouin, C., Lemechko, P., Kervarec, N., Guezennec, J. (2012). Development of a three-step derivatization assay for the localization of double bond in monounsaturated monomers of poly-betahydroxyalkanoates by GC-MS. Journal of Chromatography, B, 900: 64-70. https://doi.org/10.1016/j.jchromb.2012.05.032

[35] Reddy, A.R., Peele, K.A., Krupanidhi, S. Prabhakar, K.V., Venkateswarulu, T.C. (2019). Production of polyhydroxybutyrate from Acinetobacter nosocomialis RR20 strain using modified mineral salt medium: A statistical approach. International Journal of Environment Science and Technology, 16(6): 447-6452. https://doi.org/10.1007/s13762-018-2102-3

[36] Cavalheiro, J.M.B.T., de Almeida, M.C.M.D., Grandfils, C., da Fonseca, M.M.R. (2009). Poly(3-hydroxybutyrate) production by Cupriavidus necator using waste glycerol.
Process Biochemistry, 44(5): 509-515. https://doi.org/10.1016/j.procbio.2009.01.008

[37] Sindhu, R., Silviya, N., Binod, P., Pandey, A. (2013). Pentose-rich hydrolysate from acid pretreated rice straw as a carbon source for the production of poly-3hydroxybutyrate. Biochemical Engineering Journal, 78: 67-72. https://doi.org/10.1016/j.bej.2012.12.015

[38] Yousuf, R.G., Winterburn, J.B. (2016). Date seed characterisation, substrate extraction and process modelling for the production of polyhydroxybutyrate by Cupriavidus necator. Bioresource Technology, 222: 242251. https://doi.org/10.1016/j.biortech.2016.09.107

[39] Singh, G., Kumari, A., Mittal, A., Yadav, A., Aggarwal, N.K. (2013). Poly $\beta$-hydroxybutyrate production by bacillus subtilis NG220 using sugar industry waste water. BioMed Research International, 2013: 952641. https://doi.org/10.1155/2013/952641

[40] Sabapathy, P.C., Devaraj, S., Parthiban, A., Kathirvel, P. (2018). Bioprocess optimization of PHB homopolymer and copolymer P3 (HB-co-HV) by Acinetobacter junii BP25 utilizing rice mill effluent as sustainable substrate. Environmental Technology, 39(11): 1430-1441. https://doi.org/10.1080/09593330.2017.1330902

[41] Altaee, N., Fahdil, A., Yousif, E., Sudesh, K. (2016). Recovery and subsequent characterization of polyhydroxybutyrate from Rhodococcus equi cells grown on crude palm kernel oil. Journal of Taibah University for Science, 10(4): 543-550. https://doi.org/10.1016/j.jtusci.2015.09.003

[42] Saratale, G.D., Oh, M.K. (2015). Characterization of poly-3-hydroxybutyrate (PHB) produced from Ralstonia eutropha ATCC 17699 using an alkali-pretreated biomass feedstock. International Journal of Biological Macromolecules, $\quad 80: \quad 627-635$. https://doi.org/10.1016/j.ijbiomac.2015.07.034

[43] Mohandas, S.P., Balan, L., Lekshmi, N., Cubelio, S.S., Philip, R., Bright Singh, I.S. (2017). Production and characterization of polyhydroxybutyrate from Vibrio harveyi MCCB 284 utilizing glycerol as carbon source. Journal of Applied Microbiology, 122(3): 698-707. https://doi.org/10.1111/jam.13359

[44] Tripathi, A.D., Srivastava, S.K., Singh, R.P. (2013). Statistical optimization of physical process variables for bio-plastic (PHB) production by Alcaligenes sp. Biomass and Bioenergy, 55: 243-250. https://doi.org/10.1016/j.biombioe.2013.02.017

[45] Quillaguaman, J., Guzman, H., Van-Thuoc, D., HattiKaul, R. (2010). Synthesis and production of polyhydroxyalkanoates by halophiles: Current potential and future prospects. Applied Microbiology and Biotechnology, 85: 1687-1696. https://doi.org/10.1007/s00253-009-2397-6

[46] Joshi Kanekar, A.A., Kelkar, P.P., Sarnaik, A.S., Shouche, S.S., Wani, Y. (2007). Moderately halophilic, alkalitolerant Halomonas campisalis MCMB-365 from Lonar Lake, India. Journal of Basic Microbiology, 47(3): 213-221. https://doi.org/10.1002/jobm.200610223

[47] Choi, J., Lee, S.Y. (1999). Factors affecting the economics of polyhydroxyalkanoate production by bacterial fermentation. Applied Microbiology and Biotechnology, 51: $13-21$. https://doi.org/10.1007/s002530051357

[48] Chen, G.Q. (2009). A microbial polyhydroxyalkanoates (PHA) based bio- and materials industry. Chemical 
Society Reviews, 38(8): 2434-2446.

[49] Nath, A., Dixit, M., Bandiya, A., Chavda, S., Desai, A.J. (2008). Enhanced production and scale up studies using chess whey in fed batch culture of Methylobacterium sp. ZP24. Bioresource Technology, 99(13): 5749-5755. https://doi.org/10.1016/j.biortech.2007.10.017

[50] Li, R., Zhang, H., Qi, Q. (2007). The production of Polyhydroxyalkanoates in recombinant Escherichia coli. Bioresource Technology, 98(12): 2313-2320. https://doi.org/10.1016/j.biortech.2006.09.014

[51] Castillo, L.R., Mitchell, D.A., Freire, D.M.G. (2009). Production of Polyhydroxyalkanoates (PHAs) from waste materials and by products by submerged and solidstate fermentation. Bioresource Technology, 100(23): 5996-6009. https://doi.org/10.1016/j.biortech.2009.03.088

[52] Kavitha, G., Ramasamy, R., Dhinakarasamy, I. (2018). Polyhydroxybutyrate production from marine source and its application. International Journal of Biological Macromolecules, 111: https://doi.org/10.1016/j.ijbiomac.2017.12.155

[53] Ranganadha, R.A., Bharath, K.R., Vidyaprabhakar, K.
(2017). Isolation and Identification of PolyHydroxyButyrate (PHB) producing bacteria from Sewage sample. Research Journal of Pharmacy and Technology, 10(4): 01-05.

[54] Venkateswarulu, R.T.C., Sudhakar, P., Krupanidhi, S., Vidyaprabhakar, K. (2018). Optimization of process parameters for Polyhydroxy butyrate production from isolated Acinetobacter nosocomialis RR20 throug submerged fermentation. Current Trends in Biotechnology and Pharmacy, 12(2): 16-25.

[55] Krupanidhi, R.R.S., Venkateswarulu, T.C., Bharath Kumar, R., Sudhakar, P., Vidyaprabhakar, K. (2019). Molecular characterization of a biopolymer producing bacterium isolated from sewage sample. Current Trends in Biotechnology and Pharmacy, 13(3): 325-335.

[56] Vidyaprabhakar, R.R.K., Venkateswarulu, T.C., Krupanidhi, S., Nazneen Bobby, M., Abraham Peele, K., Sudhakar, P., Vijetha, P. (2020). Statistical optimization of Polyhydroxybutyrate(PHB) production by novel Acinetobacter nosocomialis RR20 strain using Response Surface Methodology. Current Trends in Biotechnology and Pharmacy, 14(1): 62-69. 